\title{
A 32-Year-Old Male with Recurrent Hypothermia and Hypotension of Unknown Cause
}

\author{
Ying Liu ${ }^{a}$ Lan Zhou ${ }^{a}$ Ranadhir Reddy Beereddy ${ }^{a}$ Dong Soo Kim ${ }^{a}$ \\ David Blum $^{a}$ Asok K. Lahiri ${ }^{b}$ Zev Carrey ${ }^{a}$ Dariush Alaie ${ }^{a}$ Richard L. Petrillo $^{a}$ \\ Departments of a Internal Medicine and ${ }^{b}$ Neurology, Mount Vernon Hospital, Mount Vernon, N.Y., USA
}

\section{Key Words}

Hypotension · Hypothermia · Thrombocytopenia

\begin{abstract}
Objective: To report a rare case with hypothermia, hypotension and thrombocytopenia. Clinical Presentation and Intervention: A 32-year-old male presented with recurrent hypothermia, hypotension and thrombocytopenia. He had reduced sensitivity to the environmental temperature, but had no structural brain abnormalities on MRI. The patient recovered completely with warming and supportive treatments. Conclusion: This case showed that rare cases of idiopathic hypothermia, hypotension and thrombocytopenia should be managed clinically and warming and supportive treatments were successful.

Copyright ๑ 2012 S. Karger AG, Basel
\end{abstract}

\section{Introduction}

Hypothermia with hypotension has been reported in different pathological conditions or during specific treatments [1-3]. We reported a case who presented with hypothermia with hypotension of unknown cause despite an extensive workup.

\section{KARGER}

E-Mail karger@karger.ch www.karger.com/mpp

\section{(C) 2012 S. Karger AG, Basel \\ Karger} 1011-7571/13/0222-0204\$38.00/0

Open access

This is an Open Access article licensed under the terms of the Creative Commons Attribution- NonCommercial-NoDerivs 3.0 License (www.karger.com/OA-license), applicable to the online version of the article only. Distribution for non-commercial purposes only.

\section{Case Report}

A 32-year-old obese male (BMI 37.9) was sent to the emergency room because of a decreased mental sensorium. In the past 12 years, he had had five similar episodes with hypothermia, hypotension and thrombocytopenia, happening more often in wintertime than in hot weather. Laboratory tests from a previous episode showed decreased platelet counts, as well as increased blood levels of creatinine, potassium and liver enzymes, but his brain MRI was normal. The last episode occurred at the patient's apartment in winter when there was no heating in his room. On arrival, he was confused, but had no palpitation, dizziness, headaches, chest pain, loss of consciousness, or any other symptoms. He demonstrated a reduced sensitivity to low environmental temperature, as he failed to feel cold in a cold environment as other people did.

Physical examination and laboratory tests demonstrated that his blood pressure was $78 / 44 \mathrm{~mm} \mathrm{Hg}$ (in supine position), rectal temperature $28.3^{\circ} \mathrm{C}$ (measured with Turbo Temp ${ }^{\mathrm{TM}}$ electronic thermometer), heart rate $44 \mathrm{bpm}$ and platelet count $63 \times 10^{9} / \mathrm{l}$. Liver function tests showed elevated enzymes (fig. 1a) with normal bilirubin levels. Creatinine was elevated (fig. 1b) with hypernatremia (fig. 1c). The BUN/creatinine ratio and glucose level were normal during hospitalization. Both alcohol test and urine drug screening were negative. Hormone tests are shown in table 1. Brain CT and MRI did not detect any abnormalities. Chest CT showed bilateral consolidation, consistent with pneumonia, but blood cultures were negative.

The patient was warmed up with a warming blanket and treated with intravenous normal saline, ceftriaxone and azithromycin. His mental status recovered within $8 \mathrm{~h}$, as well as his blood pres- 
sure $(110 / 75 \mathrm{~mm} \mathrm{Hg})$, heart rate $(58 \mathrm{bpm})$, and temperature $34.2^{\circ} \mathrm{C}$ and then $36.1^{\circ} \mathrm{C}$ on hospitalization day 2 . His platelet count rose to $183 \times 10^{9} / 1$ in 8 days. His liver enzymes and renal function were also normalized (fig. 1).

\section{Discussion}

The hypothermia with hypotension has been reported in different pathological conditions or during specific treatments [1-3]. However, our patient did not have any known underlying conditions. Although his chest CT suggested possible pneumonia, we excluded sepsisinduced hypothermia and hypotension because of the negative blood culture and his rapid recovery with warming and supportive treatments. This exclusion was further supported by the fact that there was no infection associated with his previous episodes. The patient's normal glucose level excluded hypoglycemia [4] or hyperglycemia [5] as the underlying cause of his hypothermia. His normal thyroid function tests excluded hypothyroidism-induced hypothermia. It has been reported that the manifestations of hypothermia may be widespread and serious, but are nonetheless reversible [1-3] as in our case.

The patient demonstrated hypernatremia and a reduced sensitivity to environmental temperature, suggesting hypothalamic dysfunction [6], but he did not have any other related neurological on endocrinological symptoms. His mild pituitary dysfunction suggested possible hypothalamic abnormality, but his normal brain MRI did not support significant hypothalamic dysfunction. Alternatively, his hypogonadism might result from his obesity. Although animal studies have shown that hypernatremia could induce hypothermia [7], this patient did not have hypernatremia in his previous episodes.

Hypothermia is known to induce thrombocytopenia [8] and hypotension, which was also seen in our patient. Thrombocytopenia of this patient was likely induced by hypothermia because after his temperature went up to $36.1^{\circ} \mathrm{C}$ with warming and supportive treatments, his platelet count was gradually trending up to the normal range by hospitalization day 8 . A bone marrow biopsy was not justified because the platelet count soon returned to normal and stayed within normal limits thereafter. His temporary hepatic injury (as shown by elevated enzymes), compromised renal function (as shown by elevated creatinine level) and the decreased mental sensorium likely resulted from hypoperfusion to these organs as a consequence of hypothermia-induced hypotension. All these

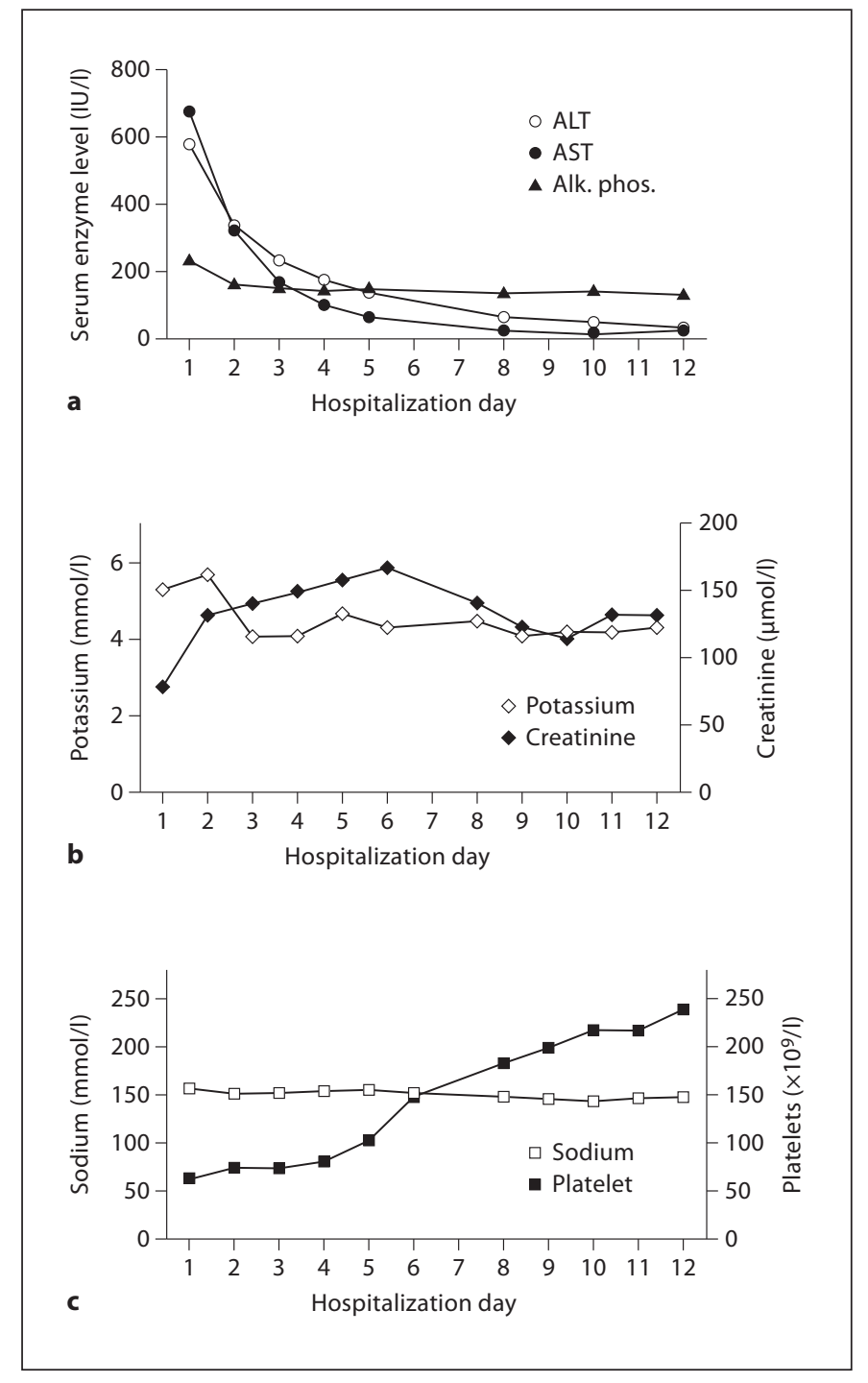

Fig. 1. Laboratory tests during hospitalization. Alk. phos. = Alkaline phosphatase.

Table 1. Hormone values during hospitalization

\begin{tabular}{lrc}
\hline Laboratory tests & Value & $\begin{array}{l}\text { Reference } \\
\text { range }\end{array}$ \\
\hline Follicle-stimulating hormone, IU/l & 0.7 & $1.6-8.0$ \\
Total testosterone, nmol/l & 0.694 & $8.36-28.7$ \\
Luteinizing hormone, IU/l & 0.2 & $1.5-9.3$ \\
Growth hormone, $\mu \mathrm{g} / \mathrm{l}$ & 0.3 & $\leq 10$ \\
Cortisol, nmol/l & 565.6 & $110-607$ \\
ACTH, pmol/l & 2.86 & $1.54-11$ \\
TSH, IU/l & 2.53 & $0.38-6.15$ \\
Free $\mathrm{T}_{4}$ on hospitalization day 2, pmol/1 & 8.49 & $9.14-23.81$ \\
Free $\mathrm{T}_{4}$ on hospitalization day 8, pmol/l & 11.07 & \\
\hline
\end{tabular}


abnormalities were reversed after warming and supportive treatments. The successful management of this case indicates that warming and supportive treatments are sufficient to treat such cases of idiopathic hypothermia, hypotension and thrombocytopenia.

\section{Conclusion}

This was a case of hypothermia with hypotension with unknown underlying diseases that was managed successfully by warming and supportive treatments.

\section{References}

1 El Ghoussein H, Hegazi MO: Hypothermia with pneumonia: a rare presentation of brucellosis. Med Princ Pract 2011;20:485-487.

$>2$ Ahn JY, Kwon HS, Ahn HC, Sohn YD: A case of myxedema coma presenting as a brain stem infarct in a 74-year-old Korean woman. J Korean Med Sci 2010;25:1394-1397.

$>3$ Seule MA, Muroi C, Mink S, Yonekawa Y, Keller E: Therapeutic hypothermia in patients with aneurysmal subarachnoid hemorrhage, refractory intracranial hypertension, or cerebral vasospasm. Neurosurgery 2009;64:86-92.
-4 Hanson PJV, Loughridge LW, Mulhall BP, Packham D: Hypothermia in hypoglycaemia. Br Med J 1984;21:1212-1213.

5 Clarke BF, Campbell IW: Multiple complications in severe diabetic ketoacidosis. A short review of the literature. Acta Diabetol Lat 1975;12:327-337.

6 Huppke P, Heise A, Rostasy K, Huppke B, Gärtner J: Immunoglobulin therapy in idiopathic hypothalamic dysfunction. Pediatr Neurol 2009;41:232-234.
Bradshaw D, Ladyman M, Stewart T: Effect of hypernatraemia and the neurohypophysial peptide, arginine vasotocin (AVT) on behavioural thermoregulation in the agamid lizard, Ctenophorus ornatus. Gen Comp Endocrinol 2007;150:34-40.

8 Milhaud D, Thouvenot E, Heroum C, Escuret E: Prolonged moderate hypothermia in massive hemispheric infarction: clinical experience. J Neurosurg Anesthesiol 2005; 17: 49-53. 